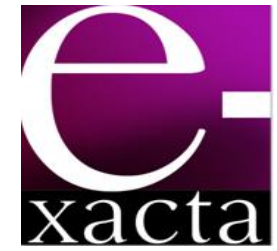

ISSN: 1984-3151

\section{AVALIAÇÃO DO POTENCIAL BIOTECNOLÓGICO DE ASPERGILLUS PARASITICUS UCP 1281 NO BIOTRATAMENTO DE EFLUENTES DA INDÚSTRIA DE LATICÍNIOS E PRODUÇÃO DE LIPÍDEOS}

\author{
EVALUATION OF BIOTECHNOLOGICAL POTENTIAL OF ASPERGILLUS \\ PARASITICUS UCP 1281 IN THE WASTEWATER BIOTREATMENT OF \\ DAIRY INDUSTRY AND LIPIDS PRODUCTION
}

1 Mestranda em Desenvolvimento de Processos Ambientais. UNICAP. Recife, PE. robertalsreis@yahoo.com.br.

2 Mestranda em Desenvolvimento de Processos Ambientais. UNICAP. Recife, PE. nairane.rs@hotmail.com.

3 Mestranda da Pós-Graduação em Biologia de Fungos. UFPE. Recife, PE. adrife.souza@gmail.com.

4 Doutoranda em Ciências Biológicas. UFPE. Recife, PE. grayce kelli@yahoo.com.br.

5 Doutorando em Biotecnologia, Rede Nordeste de Biotecnologia - RENORBIO, UFRPE. Recife, PE. macluna@bol.com.br.

6 Doutor em Biotecnologia. Núcleo de Pesquisas em Ciências Ambientais e Biotecnologia (NPCIAMB), Universidade Católica de Pernambuco, Recife, PE. calves@unicap.br.

7 Doutora em Medicina, Núcleo de Pesquisas em Ciências Ambientais e Biotecnologia (NPCIAMB), Universidade Católica de Pernambuco, Recife, PE. kao@unicap.br.

Recebido em: 09/02/2015 - Aprovado em: 22/05/2015 - Disponibilizado em: 30/05/2015

RESUMO: Neste trabalho foi realizada a identificação de Aspergillus sp (SIS 16), isolado de amostra do solo da região da Caatinga no estado de Pernambuco, e avaliado o potencial biotecnológico deste, no biotratamento de efluentes da indústria láctea. $O$ isolado foi identificado, através das características macroscópicas e microscópicas como A. parasiticus (UCP1281). O potencial para biotratamento de efluentes ricos em lipídeos foi analisado avaliando-se a produção de lipase por A. parasiticus (UCP1281) através de fermentação submersa em agitador orbital em meio padrão, na presença de óleo de oliva $0,5 \mathrm{~g} \mathrm{~L}^{-1}$ durante $120 \mathrm{~h}$ nas temperaturas de $28^{\circ} \mathrm{C}$ e $37{ }^{\circ} \mathrm{C}$, $150 \mathrm{rpm}$. Foram determinados a curva de crescimento, $\mathrm{pH}$ e atividade lipolítica. Os resultados obtidos evidenciaram que com $96 \mathrm{~h}$, a $28{ }^{\circ} \mathrm{C}$, foi obtida a melhor atividade lipolítica alcançados 5,2 U mL ${ }^{-1}$. Considerandose os resultados, foram realizados os ensaios utilizando os resíduos da indústria láctea (soro de leite e resíduo de sorvete) através de um planejamento fatorial completo de $2^{2}$, utilizando as mesmas condições do ensaio anterior. Foram determinados também, além dos parâmetros anteriores, o percentual de lipídeos acumulado na biomassa de A. parasiticus (UCP1281). Os resultados obtidos evidenciaram que a melhor condição foi no ensaio 4 (45 \% de resíduo de sorvete e $30 \%$ de soro de leite), com produção de biomassa de $68,1 \mathrm{~g} \mathrm{~L}^{-1}$, a atividade lipolítica de $20,0 \cup \mathrm{mL}^{-1}$ e o maior percentual de acúmulo de lipídeos na biomassa $67,61 \%$. Os resultados demonstraram o 
potencial deste isolado no biotratamento de efluentes da indústria láctea, assim como para a produção de lipídeos, uma vez que o micro-organismo converteu eficientemente o soro de leite e o resíduo de sorvete em biomassa com alto percentual de lipídeos nas suas células.

PalAVRAS-Chave: Fungo filamentoso. Caatinga. Atividade lipolítica.

ABSTRACT: In this work, the identification of Aspergillus sp (SIS 16), isolated from the soil sample in Caatinga region in the state of Pernambuco, and rated the biotechnological potential of it in the biotreatment of dairy industry effluents. The identification took place through the macroscopic and microscopic characteristics as $A$. parasiticus (UCP1281). The potential for biotreatment of wastewater rich in lipids was analyzed by evaluating the lipase production by $A$. parasiticus (UCP1281) through submerged fermentation in an orbital shaker in standard medium in the presence of olive oil $0.5 \mathrm{~g} \mathrm{~L}^{-1}$ for 120 hours at temperatures $28{ }^{\circ} \mathrm{C}$ and $37{ }^{\circ} \mathrm{C}, 150 \mathrm{rpm}$. Were determined the growth curve, $\mathrm{pH}$ and lipase activity. The results showed that with 96 hours, at $28{ }^{\circ} \mathrm{C}$ was obtained the best lipase

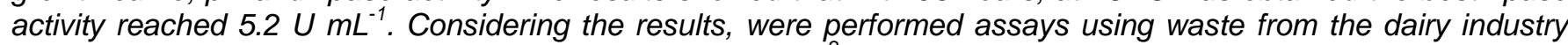
(whey and cream residue) through a full factorial design of $2^{2}$ using the same conditions as the previous test. Were also determined in addition to the above parameters, the cumulative percentage of lipid in the biomass of $\underline{A}$. parasiticus (UCP1281). The results showed that the best condition was the test 4 (45\% of ice cream residue and $30 \%$ whey), with biomass of $68,1 \mathrm{~g} \mathrm{~L}^{-1}$, the lipase activity of $20.0 \mathrm{U} \mathrm{mL}^{-1}$ and the highest percentage of lipid accumulation in biomass $67.61 \%$. The results demonstrated the potential of this isolate in the biotreatment of dairy industry effluents, as well as for the production of lipids, since the microorganism efficiently converted whey cream and waste biomass with a high percentage of lipids in their cells.

KEYWORDS: Filamentous fungi. Caatinga. Lipolytic activity

\section{INTRODUÇÃO}

O solo armazena organismos vivos e proporciona altas taxas metabólicas que ocorrem em seu interior, por existirem raízes e a presença de decomposição da matéria orgânica. É nesta região, a rizosfera, onde existe uma maior atividade microbiana, em razão da presença de exsudatos e secreções radiculares, que representam a maior parte do carbono disponível para os micro-organismos. Sem a influência das raízes e da atividade da biota que funcionam de forma simbiótica, - solo pode ser considerado oligotrófico ou relativamente pobre em fontes de carbono disponíveis (ARAÚJO, MONTEIRO, 2007; BARROS, 2012; PLANTE, STONE, MCGILL, 2014).

O isolamento de novos micro-organismos de ambientes onde se conhece pouco da biodiversidade microbiana, como a Caatinga nordestina, tem incentivado, nas últimas décadas, um aumento nos estudos de bioprospecção microbiana voltada para pesquisas envolvendo o potencial biotecnológico desses organismos e, assim, proporcionar a descoberta de novos produtores de compostos bioativos de alto valor agregado (MONTEIRO, 2012;
LIU et al., 2012; SMRITHI et al., 2013; MONCIARDINI et al., 2014).

A Caatinga é um ecossistema do sertão nordestino. Estende-se por cerca de $735.000 \mathrm{~km}^{2}$, sendo limitada a leste e a oeste pelas florestas Atlântica e Amazônica, respectivamente, e ao sul pelo Cerrado (REIS, 1976). Apresenta um clima semi-árido, quente e com baixos índices pluviométricos, baixa umidade relativa do ar e altas temperaturas durante quase todo o ano (COSTA et al., 2014).

O interesse pela produção de enzimas e o avanço da tecnologia enzimática vem aumentando gradativamente nos últimos anos, favorecendo o desenvolvimento de áreas na engenharia de proteínas, contribuindo assim para a ampliação do uso de enzimas, principalmente as de origem microbiana, nos processos industriais.

As enzimas que hidrolisam os lipídios são denominadas de lipases e podem ser encontradas em animais, vegetais e micro-organismos (CASTRO et al., 2009; LEE et al., 2004; VADLAMANI; PARCHA, 2011; BRANDELLI, SALA, KALIL, 2015). As lipases microbianas são amplamente diversificadas em suas 
propriedades enzimáticas e especificidade de substratos, o que as torna muito atrativas para aplicação industrial (ROVEDA; HEMKEMEIER; COLLA, 2010; COLLA; REINEHR; COSTA, 2012). A produção de lipases nos micro-organismos pode ser influenciada diretamente por diferentes fatores, como fonte de carbono, concentração de oxigênio dissolvido, temperatura e $\mathrm{pH}$ do meio, e condições de aeração (HASAN; SHAH; HAMEED, 2006; CAMMAROTA, FREIRE, 2006; MARTINS, KALIL, COSTA, 2008; LIMA et al., 2014).

A produção de lipase por fungos filamentosos tem sido estudada através de fermentação submersa (FS) e fermentação estado sólido (FES). Embora a FS seja mais comum nos processos industriais, a FES tem sido explorada principalmente devido às vantagens, como espaços requeridos e efluentes produzidos (SHARMA, 2001). E para os fungos filamentosos como Aspergillus, Penicillium, Mucor e Rhizopus, a FES apresenta condições similares ao seu habitat natural (CAMMAROTA; FREIRE, 2006).

Os fungos filamentosos do gênero Aspergillus se destacam como excelentes produtores de metabólitos secundários de interesse industrial e ambiental, pois apresentam uma elevada taxa de crescimento e um grande termo tolerância, o que favorece estudos de seleção e produção de bioprodutos de alto valor agregado (GOPINATH et al., 2013; MALDONATO, MACEDO, RODRIGUES, 2014; ZEN et al., 2014).

Inúmeras espécies de Aspergillus têm sido relatadas para a produção de lipase (CONTESINI et al., 2010; DAMASCENO; CAMMAROTA; FREIRE, 2012; DUMORE, MUKHOPADHYAY, 2012; SINGH, MUKHOPADHYAY, 2012; COLLA; REINEHR; COSTA, 2012; DOBREV et al., 2014).

As lipases têm sido empregadas em sistemas para o pré-tratamento e tratamento de efluentes com altas concentrações de óleos e gorduras (CAMMAROTA et al., 2013). Efluentes industriais gerados em frigoríficos, abatedouros, indústrias de alimentos e laticínios, em geral, possuem elevados teores de demanda bioquímica e química de oxigênio (DBO e $D Q O)$, tendo em vista que o conteúdo de gorduras aumenta a concentração de matéria orgânica. (MENDES et al., 2005; GASPARIN et al., 2012). Diversos estudos realizados utilizando os resíduos desses efluentes para formulação de meios de produção têm obtido sucesso, principalmente utilizando o planejamento fatorial para minimizar a quantidade de experimentos e os custos de elaboração de meios de produção (LIU et al., 2008; NOTARNICOLA et al., 2012; JOSHI; WALIA; RANA, 2012; HOSSEINPOUR et al., 2012; PANESAR, KENNEDY, 2012; LIN et al., 2013; WANG et al., 2013; SUNG, 2013; AGGELOPOULOS et al., 2014; PLEISSNER et al., 2014; MARQUES et al., 2014).

A viabilidade da utilização de fungos na produção de lipídeos para diversos fins (biodiesel, ácidos graxos, bio-óleo) e de SCP (single cell protein) tem sido demonstrada por inúmeros autores (ABU-ELREESH et al., 2013; NANGUL et al., 2013; ABU-ELREESH; ABDEL-HALEEM, 2014; BABU et al., 2014; BHANJA et al., 2014).

Neste trabalho foi realizada a identificação da amostra de Aspergillus sp (SIS 16) e a avaliação do potencial da amostra no biotratamento de efluentes da indústria láctea através do crescimento, atividade lipolítica e a capacidade de produzir e acumular lipídeos na biomassa.

\section{MATERIAIS DE MÉtodos}

\subsection{MiCRO-ORGANISMO}

O micro-organismo foi isolado de amostra do solo da Caatinga, município de Serra Talhada, mesorregião Sertão - PE, sendo codificado como SIS 16. Mantido 
no Banco de Culturas do Núcleo de Pesquisas em Ciências Ambientais e Biotecnologia (NPCIAMB) da Universidade Católica de Pernambuco (UNICAP).

\subsection{IDENTIFICAÇÃo E CARACTERIZAÇÃo MORFOLÓGICA}

A identificação e a caracterização morfológica da amostra foram realizadas através da metodologia descrita por Klick (2002), por meio da chave para identificação da espécie. A amostra foi cultivada nos meios Ágar Czapek autolisado de levedura - (CYE) (PITT, 1979) a $25^{\circ} \mathrm{C}$ e $37^{\circ} \mathrm{C}$, e Extrato de Malte Àgar (MEA) a $25{ }^{\circ} \mathrm{C}$. As características macroscópicas foram determinadas pela textura da colônia, grau de esporulação, cor dos conídios, textura e cor do micélio, presença de cores, pigmentos e exsudado.

Para análise microscópica, foram preparadas lâminas, para observação das estruturas microscópicas como: comprimento, largura e textura dos conidióforos, forma da cabeça conidial, diâmetro da vesícula, comprimento das métulas e fiálides, diâmetro, forma, textura presença ou ausência de conídios e ascósporos, forma e cor do cleistotécio/esclerócios.

\subsection{PrÉ-INOCULO}

Foram utilizadas placas de Petri contendo o meio ágar Sabouraud (acrescido de azeite de oliva para aclimatação) e incubadas a $28 \stackrel{\circ}{\mathrm{C}}$ durante 7 dias.

\subsection{CinÉticA de CRESCIMENTO E DE PROduÇÃo DE LIPASE EM MEIO CONVENCIONAL}

A cinética de crescimento e a produção de lípase foram realizadas através de fermentação submersa, utilizando-se uma concentração de células padronizada de $10^{7}$ esporos $\mathrm{mL}^{-1}$, em $100 \mathrm{~mL}$ de meio convencional (glicose $\left(0,25 \mathrm{~g} \mathrm{~L} \mathrm{~L}^{-1}\right) ; \quad \mathrm{MgSO}_{4} \cdot 7 \mathrm{H}_{2} \mathrm{O}$ $\left(0,05 \mathrm{~g} \mathrm{~L}^{-1}\right) ; \mathrm{K}_{2} \mathrm{HPO}_{4}\left(0,175 \mathrm{~g} \mathrm{~L}^{-1}\right)$; extrato de levedura $\left(0,1 \mathrm{~g} \mathrm{~L}^{-1}\right)$; óleo de oliva $\left(0,5 \mathrm{~mL} \mathrm{~L}^{-1}\right) ; \mathrm{pH}=7$, utilizando duas temperaturas de incubação $\left(28^{\circ} \mathrm{C}\right.$ e $\left.37^{\circ} \mathrm{C}\right)$, $120 \mathrm{~h}, 150 \mathrm{rpm}$.

As amostras foram coletadas com intervalo de $24 \mathrm{~h}$ e filtradas. O liquido metabólico foi utilizado para a determinação da atividade lipolítica e do pH. A biomassa foi utilizada para a determinação da cinética de crescimento e extração de lipídeos totais.

\subsection{DETERMINAÇÃo DA BIOMASSA MICROBIANA}

A determinação da biomassa foi feita através de gravimetria. A massa micelial foi lavada e filtrada em papel de filtro, transferida para a estufa a $50^{\circ} \mathrm{C}$ para secagem, em seguida transferida para o dessecador até peso constante.

\subsection{DeterminaçÃo dA ATIVIDADE LIPOLÍTICA}

A atividade lipolítica das amostras foi detectada utilizando-se a metodologia descrita por Soares et al. (1999). Através da reação de $5 \mathrm{~mL}$ de emulsão de óleo de oliva e goma arábica (7\%), $2 \mathrm{~mL}$ de tampão fosfato de sódio $(0,1 \mathrm{M}), \mathrm{pH}$ 7,0 e $1 \mathrm{~mL}$ do líquido metabólico. A mistura foi agitada em agitador orbital a $82 \mathrm{rpm}, 37^{\circ} \mathrm{C}$, durante 10 minutos.

A reação foi paralisada através da adição de $10 \mathrm{~mL}$ de acetona-etanol-água (1:1:1 v/v), para liberação dos ácidos graxos livres presentes na mistura, em seguida foi realizada a titulação com uma solução de $\mathrm{KOH}$ $(0,04 \mathrm{~N})$ na presença do indicador fenolftaleína. Os ensaios foram realizados em triplicata e a atividade enzimática foi determinada através da seguinte relação: uma unidade da atividade lipolítica $\left(\mathrm{U} \mathrm{mL}^{-1}\right)$ é definida como a quantidade da enzima bruta que libera $1 \mu \mathrm{mL}^{-1}$ de ácido graxo por minuto. 
Para os cálculos da atividade enzimática da lipase presente na amostra foi utilizada a seguinte Eq. 1 :

$\mathrm{AE}\left(\mathrm{U} \mathrm{mL}^{-1}\right)=\frac{(\mathrm{Va}-\mathrm{Vb}) \times \mathrm{N} \times 1000}{\mathrm{t} \times \mathrm{Vc}}$

Onde:

$\mathrm{AE}=$ Atividade lipolítica;

$\mathrm{Va}=$ Volume da amostra titulada $(\mathrm{mL})$;

$\mathrm{Vb}=$ Volume do branco titulado $(\mathrm{mL})$;

$\mathrm{N}=$ Normalidade da solução de $\mathrm{KOH}\left(\mathrm{mol} \mathrm{L}^{-1}\right)$;

$\mathrm{t}==$ Tempo de reação $(\min$.$) ;$

$\mathrm{Vc}=$ Volume da amostra utilizada na reação $(\mathrm{mL})$.

\subsection{Avaliação da PRodução de lipase e} CONVERSÃO DE RESÍDUOS DA INDÚSTRIA LÁCTEA

\section{EM LIPÍDEOS}

Após a produção da lipase em meio convencional, foram realizados ensaios de formulação de meios com resíduos da indústria láctea (soro de leite $(S L)$ e resíduo de sorvete (RS), através de um planejamento fatorial $2^{2}$ com 4 repetições no ponto central (TAB. 1).

Tabela 1

Matriz do planejamento fatorial para formulação de meios alternativos

\begin{tabular}{c|c|c|c}
\hline Variáveis & -1 & 0 & +1 \\
\hline RS (\%) & 15 & 30 & 45 \\
SL (\%) & 10 & 20 & 30 \\
\hline
\end{tabular}

RS- resíduo de sorvete; SL - Soro de leite

Os frascos foram incubados em um agitador orbital a $150 \mathrm{rpm}$, a $28^{\circ} \mathrm{C}$, por $120 \mathrm{~h}$. Ao término dos ensaios, a biomassa foi separada do líquido metabólico por centrifugação a $10.000 \mathrm{~g}$ durante 15 minutos. Com o líquido metabólito, foram realizadas determinações da atividade lipolítica e de $\mathrm{pH}$. A biomassa foi utilizada para determinação da curva de crescimento e lipídeos totais.
A análise dos dados e gráficos foi realizada utilizandose o software Statistic 7.0, e a significância dos resultados foram testadas $(p \leq 0,05)$.

Os experimentos foram realizados em frascos de Erlenmeyer de $250 \mathrm{~mL}$ em um volume de $100 \mathrm{~mL}$ de meio, sob agitação de $150 \mathrm{rpm}$, a temperatura de $28^{\circ} \mathrm{C}$, durante $120 \mathrm{~h}$.

\subsection{EXTRAÇÃO E QUANTIFICAÇÃo DOS LIPÍDEOS TOTAIS}

Os lipídeos totais da biomassa foram extraídos utilizando-se $1,0 \mathrm{~g}$ da biomassa liofilizada que foi submetida à extração com a mistura de solventes: clorofórmio:metanol (2:1 v/v), agitado por 15 minutos e homogeneizado por $24 \mathrm{~h}$. Em seguida a amostra foi centrifugada $5000 \mathrm{~g}$ por 5 minutos, o sobrenadante contendo os lipídeos foi retirado e reservado em frasco. Esse processo foi repetido sucessivamente utilizando-se as misturas de solventes clorofórmio:metanol na proporção de 1:1 v/v e 1:2 v/v.

Os extratos foram reunidos e evaporados em rotaevaporador e ressuspensos em $2 \mathrm{~mL}$ de hexano, evaporados com de nitrogênio e mantidos em dessecador até peso constante (MANOCHA et al., 1980).

O percentual de lipídeos totais presentes da biomassa foi determinado pelo método gravimétrico utilizando-se a Eq. 2:

Lipídeos Totais $(\%)=\frac{\text { massa de lipídeos } \times 100}{\text { biomassa seca }(\mathrm{g})}$ 


\section{Resultados e Discussão}

\subsection{IDENTIFICAÇÃo E Caracterização MORFOLÓGICA}

As características macroscópicas do crescimento radial das colônias crescidas em placas com o meio Agar Czapek autolisado de levedura (CYE) estão apresentadas na FIG. 1. A colônia apresentou um diâmetro de crescimento de $70 \mathrm{~mm}$ em $96 \mathrm{~h}$ a $25^{\circ} \mathrm{C}$ e $37^{\circ} \mathrm{C}$ de temperatura. Quanto à coloração da colônia, foram observados micélios brancos e flocosos, conídios de cor verde escura, e de reverso incolor. $\mathrm{O}$ crescimento da colônia em Extrato de Malte Àgar (MEA), observado na FIG. 2, também apresentou crescimento flocoso, e conídios de cor oliva e reverso da colônia amarelada.

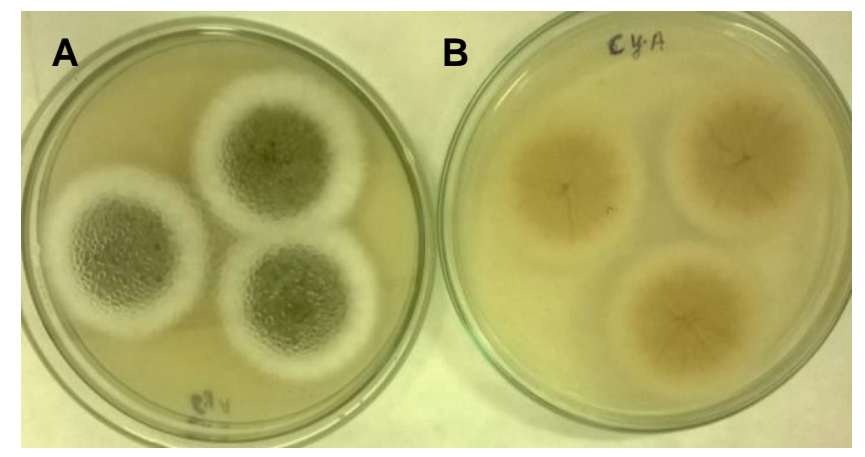

Figura 1 - Crescimento radial no meio de (CYE) verso (A) e reverso (B) da placa.

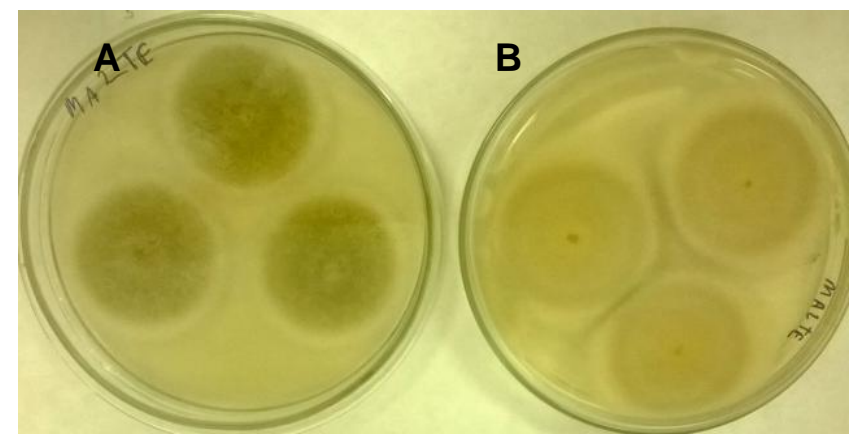

Figura 2 - Crescimento radial de Aspergillus sp no meio de $M E A$ verso $(A)$ e reverso (B) da placa).
A análise microscópica do crescimento da amostra no meio CYE permitiu a visualização de hifas cabeças do tipo radial, conidióforos de superfície finamente rugosa e incolor, vesículas alcançando entre 30 a $35 \mu \mathrm{m}$ esféricas a piriformes; predominantemente unisseriado, com pouca bisseriação (métulas e fiálides), diferenciando-se da espécie Aspergillus flavus, que apresenta seriação variada, métulas alcançando até $9 \mu \mathrm{m}$ e fiálides entre 8 a $11 \mu \mathrm{m}$ de comprimento. Conídios globosos e rugosos entre $3,5 \mu \mathrm{m}$ a $6 \mu \mathrm{m}$ de diâmetro, distinguindo da espécie $A$. flavus (KLICH, 2002).

De acordo com identificação clássica, com base nas características macroscópicas e microscópicas, o isolado foi identificado como Aspergillus parasiticus (FIG. 3).

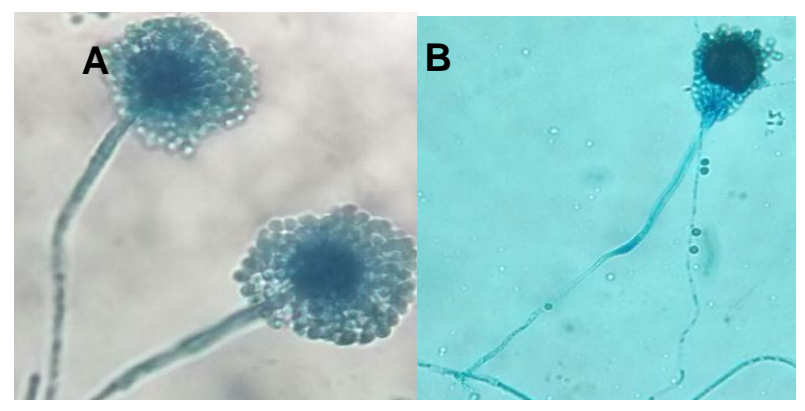

Figura 3 - Micrografia da amostra de Aspergillus parasiticus crescida no meio de CYE. A conidiosporos com conídios globosos e rugoso e Bvesículas com poucas seriação bisseriada métulas e fiálides)

\subsection{Cinética de CREscimento A. parasiticus}

\subsubsection{MEIO PADRÃO}

O perfil de crescimento de $A$. parasiticus (SIS 16) para produção de biomassa e atividade lipolítica (óleo de oliva, a $28 \stackrel{\circ}{\circ}$ e $37 \stackrel{\circ}{ } \mathrm{C}$, por 120 h) está descrita nas FIG. 4 e 5, respectivamente. 


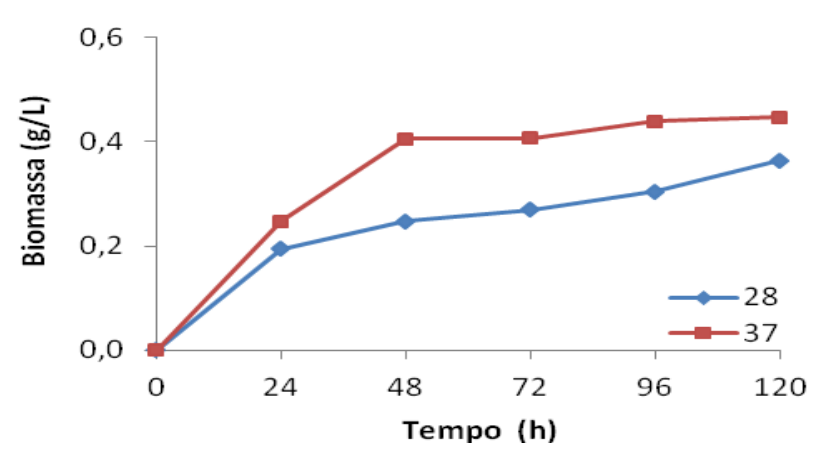

Figura 4 - Perfil de crescimento de Aspergillus. parasiticus, em $120 \mathrm{~h}$ de cultivo em meio padrão nas temperaturas 28 e $37^{\circ} \mathrm{C}$.

Foi constatado que, quando cultivada à temperatura de $37 \stackrel{\circ}{\circ}$, a biomassa produzida foi $23 \%$ maior que a $28 \stackrel{\circ}{ } \mathrm{C}$. O pH do meio de cultivo se manteve entre $6,1 \mathrm{a}$ 7,0 .

De acordo com Macedo (2009), espécies do gênero Aspergillus crescem em pH que varia de 2,0 a 11,0, assim como a velocidade de crescimento diminui quando $\circ \mathrm{pH}$ afasta-se do ótimo (geralmente próximo a 5,0$)$.

Os resultados da atividade lipolítica de $A$. parasiticus (SIS 16) podem ser observados na FIG. 5. A maior atividade enzimática foi obtida após $96 \mathrm{~h}$ de cultivo $\left(5,2 \cup \mathrm{mL}^{-1}, 28^{\circ} \mathrm{C}\right)$.

As enzimas produzidas por bactérias e fungos têm sido utilizadas no biotratamento de efluentes de diversas origens. Espécies do gênero Aspergillus são conhecidamente produtoras de lipases e têm sido estudadas para diferentes aplicações. Por exemplo, na degradação de resíduos resultantes de variados processos industriais como produção de óleo, biodiesel, alimentos, etc. (CAMMAROTA; FREIRE, 2006; CONTESINI et al., 2010; TUDORACHE et al., 2012; COLLA; COLLA; REINEHR; COSTA, 2012; DEVI; SIVAKUMAR, 2014; DOBREV et al., 2014; LAACHARI et al., 2015; NAZ; JADHAV, 2015).

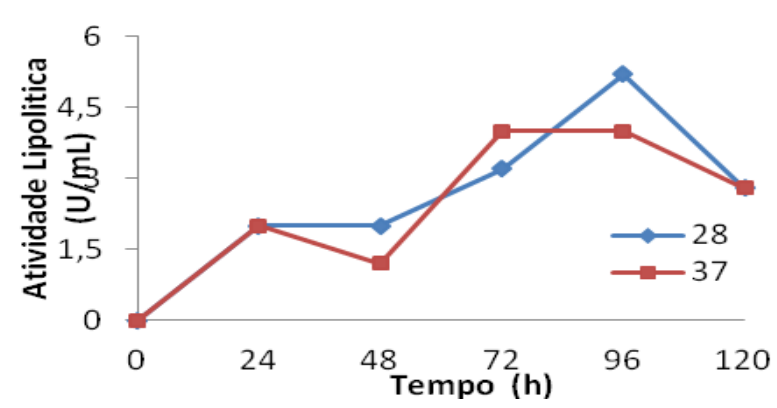

Figura 5 - Perfil atividade lipolítica de $A$. parasiticus (SIS 16), em $120 \mathrm{~h}$ de cultivo em meio padrão nas temperaturas 28 e $37^{\circ} \mathrm{C}$.

\subsubsection{MEIOS CONTENDO RESíduOS LÁCTEOS}

Os resultados (biomassa, atividade lipolítica e lipídeos totais) obtidos nos ensaios com a amostra de $A$. parasiticus (SIS 16), nos meios formulados com soro de leite e resíduo de sorvete, através de um planejamento fatorial $2^{2}$, com estão descritos na TAB. 2.

Tabela 2

Produção de biomassa $\left(\mathrm{g} \mathrm{L}^{-1}\right), \mathrm{AE}$ - atividade lipolítica $\left(\mathrm{U} \mathrm{mL}^{-1}\right)$ e lipídeos totais (\%), obtidos através do planejamento fatorial $2^{2}$, em $120 \mathrm{~h}$ de cultivo.

\begin{tabular}{c|c|c|c}
\hline Ensaios & $\begin{array}{c}\text { Biomassa } \\
\left(\mathbf{g ~ L}^{-1}\right)\end{array}$ & $\begin{array}{c}\mathbf{A E} \\
\left(\mathbf{U ~ m L}^{-1}\right)\end{array}$ & $\begin{array}{c}\text { Lipídeos } \\
\text { totais (\%) }\end{array}$ \\
\hline 1 & 3,9 & 4,0 & 9,65 \\
\hline 2 & 37,1 & 4,0 & 5.35 \\
\hline 3 & 50.9 & 4.0 & 36.23 \\
\hline $\mathbf{4}$ & $\mathbf{6 8 . 1}$ & $\mathbf{2 0 . 0}$ & $\mathbf{6 7 . 6 1}$ \\
\hline 5 & 53.6 & 5.0 & 34.45 \\
\hline 6 & 53.5 & 5.2 & 34.14 \\
\hline 7 & 54.7 & 5.0 & 33.79 \\
\hline 8 & 54.5 & 5.6 & 33.87 \\
\hline
\end{tabular}

Matriz decodificada

A melhor condição foi no ensaio 4 ( $45 \%$ de resíduo de sorvete e $30 \%$ de soro de leite), apresentando maior 
produção de biomassa $\left(68,1 \mathrm{~g} \mathrm{~L}^{-1}\right)$, atividade lipolítica $\left(20,0 \cup \mathrm{mL}^{-1}\right)$ e de lipídeos totais $(67,61 \%)$, (FIG. 6). $\mathrm{O} \mathrm{pH}$ variou na faixa de 6,1 a 7,6 , permanecendo próximo da neutralidade.

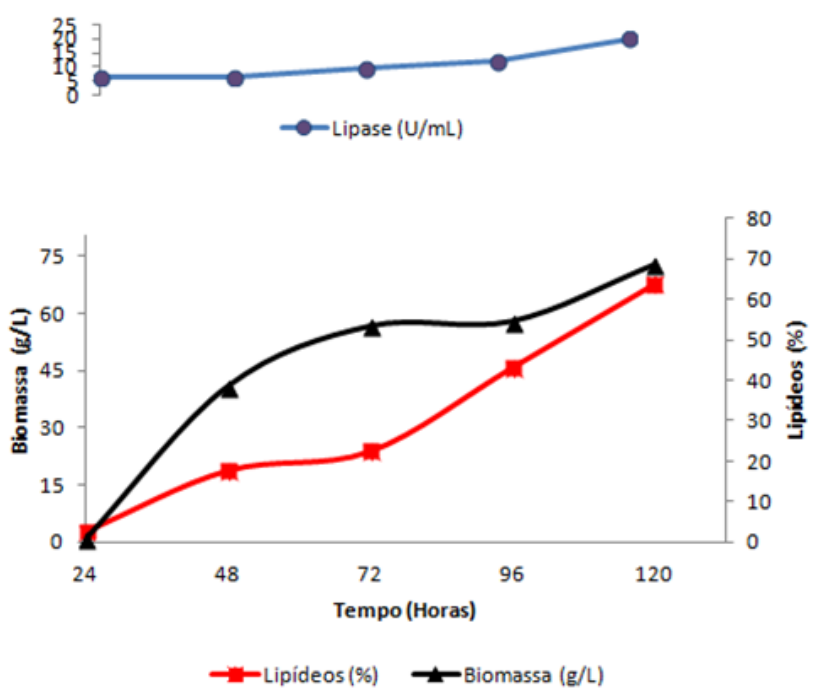

Figura 6 - Curva de crescimento (biomassa), lipídeos totais e determinação da atividade lipolítica de $A$. parasiticus (SIS 16), cultivada em meios compostos de resíduos da indústria de laticínios (soro de leite e resíduo de sorvete), através de um planejamento fatorial $2^{2}$.

Esse resultado representa um percentual superior a $74 \%$ da atividade lipolítica em relação ao meio padrão, demonstrando que a introdução dos resíduos (soro de leite e resíduo de sorvete) na composição do meio, estimulam a produção e atividade enzimática.

Na FIG. 7 estão os diagramas de Pareto relacionados com a produção de lipase (FIG. 7A) e a produção de lipídeos (FIG. 7B). Os resultados obtidos mostram a significância dos resultados com 95\% de confiança representada pela linha tracejada que corresponde a $p=0,05$, confirmando os resultados obtidos na TAB. 2.
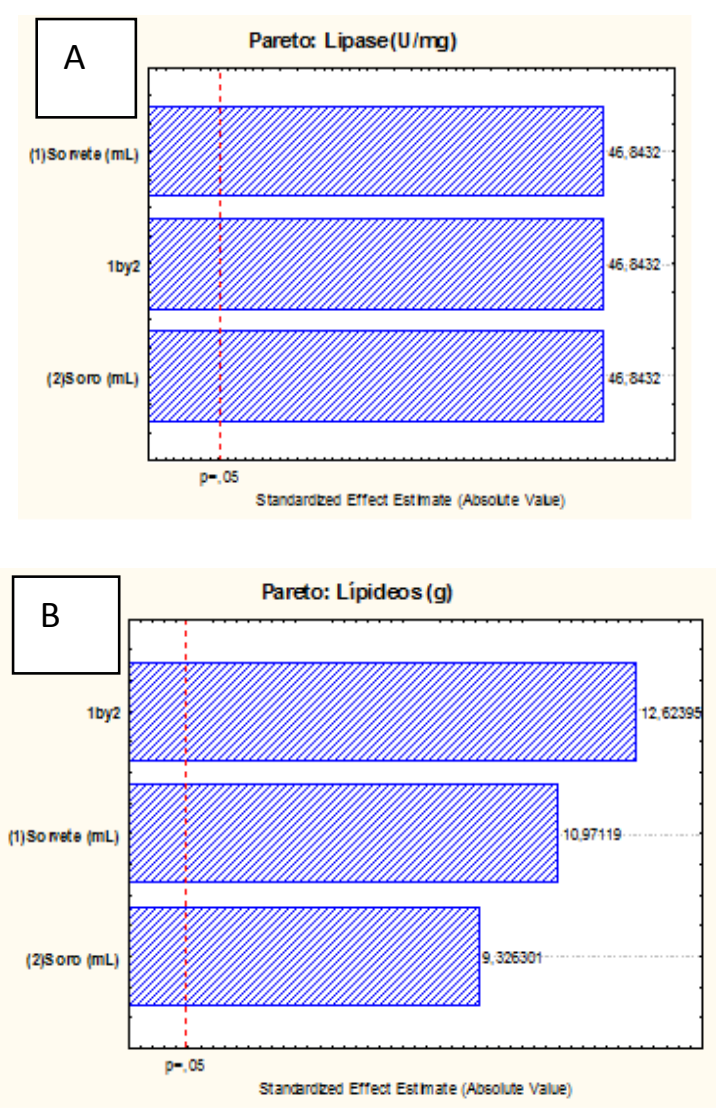

Figura 7 - Diagrama de Pareto: A - Produção de lipase e B - Produção de lipídeos.

No diagrama de Pareto (FIG. 7 A-B), é visível que as variáveis (SL) e (RS) superaram o valor de $p=0,05$, obtendo assim um nível de confiança de $95 \%$, confirmando que esses valores são estatisticamente significativos. A interação dos resíduos influenciou positivamente nas variáveis respostas (FIG. 7B).

Espécies do gênero Penicillium, $P$. citrinum e $P$. restrictum apresentam ótima produção de lipase, com baixo custo de produção (SILVA; BRUNO; CASTRO, 2009; CASTILHO et al., 2000). Silva, Bruno e Castro (2009) realizaram ensaios de produção de lipases extracelulares com o $A$. parasiticus e obtiveram uma atividade lipolítica de 69,9 ( $\left.\mathrm{U} \mathrm{mL}^{-1}\right)$ após $72 \mathrm{~h}$ de cultivo. 


\subsection{CONVERSÃO DE RESÍDUOS DA INDÚSTRIA LÁCTEA EM LIPÍDEOS}

A porcentagem de lipídeos presentes no meio de resíduo (tempo zero, sem o inóculo) do ensaio 4 e no tempo final da fermentação $(120 \mathrm{~h})$ determinou a porcentagem de tratamento.

Os resultados demonstraram que 0 meio contendo resíduos da indústria láctea apresenta um conteúdo elevado de lipídeos (59,51\%), que foi degradado e utilizado como fonte de nutrientes para crescimento e desenvolvimento do fungo, uma vez que ao final do cultivo foi observado que essa percentagem de lipídeos reduziu para $0 \%$. A. parasiticus (SIS 16) converteu o conteúdo do resíduo rico em lipídeos em biomassa com uma porcentagem de $67,81 \%$ de lipídeos totais (ensaio 4).

Segundo subhash (2014) a variação na síntese de lipídeos no citoplasma por fungos é principalmente dependente do tipo de modo nutricional seguido pelos fungos à disponibilidade de nutrientes de carbono. Yarrowia lipolytica tem sido exaustivamente estudada na produção de lipase e outras moléculas bioativas como biossurfactantes, assim como sua utilização no tratamento e pré-tratamento de resíduos agroindustriais com conversão em biomassa útil (single cell protein) e lipase com baixo custo de produção e de alto valor agregado (PAPANIKOLAOU et al., 2007; ZEN, 2014).

\section{CONSIDERAÇõES FINAIS}

Diante dos resultados obtidos, constatou-se que o fungo Aspergillus parasiticus (SIS 16) isolado solo da Caatinga do Estado de Pernambuco, demostrou um elevado potencial biotecnológico para tratamentos de efluentes gordurosos das indústrias lácteas, considerando a produção da lipase, assim como, a conversão desses resíduos em lipídeos, que podem ser utilizados em diferentes setores industriais.

O uso de resíduos da agroindústria, como da indústria láctea, na formulação de meios alternativos tem gerado resultados promissores, uma vez que esses resíduos são ricos em nutrientes que auxiliam na produção de diversos compostos bioativos e podem ser encontrados em grande quantidade. A utilização de planejamento fatorial para obtenção das melhores condições de produção favorece e facilita os estudos envolvendo a conversão nesses metabólitos secundários nos processos de utilização de resíduos.

\section{Agradecimentos}

Os autores agradecem ao Projeto SISBIOTA-CNPq, FACEPE, CAPES e a UNICAP, pelo suporte financeiro para realização desse trabalho, e ao Núcleo de Pesquisas em Ciências Ambientais e Biotecnologia (NPCIAMB) da Universidade Católica de Pernambuco (UNICAP) pela infraestrutura da execução de toda parte experimental.

\section{REFERÊNCIAS}

ABU-ELREESH, G. et al. An effective lipid-producing fungal sp. strain DGB1 and its use for biodiesel production. African Journal of Biotechnology, v. 12, n. 34, p. 5347-5353, 2013.

ABU-ELREESH, G.; ABD-EL-HALEEM, D. Promising oleaginous filamentous fungi as biodiesel feed stocks:
Screening and identification. European Journal of Experimental Biology, v. 4, n. 1, p. 576-582, 2014.

AGGELOPOULOS, T. et al. Solid state fermentation of food waste mixtures for single cell protein, aroma volatiles and fat production. Food chemistry, v. 145, p. 710-716, 2014. 
ARAÚJO, A. S. F.; MONTEIRO, R. T. R. Indicadores biológicos de qualidade do solo. Biosci. Uberlândia, v. 23, n. 3, p. 66-75, 2007.

BABU, M. et al. Production of Single Cell Protein using Kluveromyces marxianus isolated from paneer whey. International Journal of Biomedical and Advance Research, v. 5, n. 5, p. 255-257, 2014.

BARROS, R. P. Diversidade de fungos em um vertissolo com adição de vinhaça na cultura de canade-açúcar (Saccharum officinarum). Revista Uniabeu, Alagoas, v. 5, n. 10, p.181-195, 2012.

BHANJA, A. et al. Comparative Studies of Oleaginous Fungal Strains (Mucor circinelloides and Trichoderma reesel) for Effective Wastewater Treatment and Bio-Oil Production. Biotechnology research international, v. 2014, 2014.

BRANDELLI, A; SALA, L.; KALIL, S. J. Microbial enzymes for bioconversion of poultry waste into added-value products, Food Research International, 2015 disponível em http://dx.doi.org/10.1016/j.foodres. Acesso em 15 jan. 2015.

CAMMAROTA, M. C.; FREIRE, D. M. G. A review on hydrolytic enzymes in the treatment of wastewater with high oil grease content. Bioresource Technology, Essex, v. 97, p. 2195-2210, 2006.

CAMMAROTA, M. C. et al. The effect of enzymatic pre-hydrolysis of dairy wastewater on the granular and immobilized microbial community in anaerobic bioreactors. Environmental Technology, v. 34, n. 4, p. 417-428, 2013.

CASTILHO, L. R. et al. Economic analysis of lipase production by Penicillium restrictum in solid-state and submerged fermentations. Biochemical Engineering Journal, v. 4, n. 3, p. 239-247, 2000.

CASTRO, B M. et al. Cholesterol-rich Fluid Membranes Solubilize Ceramide Domains Implications for the structure and dynamics of mammalian intracellular and plasma membranes. Journal of Biological Chemistry, v. 284, n. 34, p. 22978-22987, 2009.

CASTRO, H. F.; MENDES, A. A.; SANTOS, J. C. Modificações de óleos e gorduras por biotransformação. Química Nova, v. 27, n. 1, p. 146156, 2004.

COLLA, L. M.; REINEHR, C. O.; COSTA, J. A. V. Aplicações e produção de lipases microbianas. Revista de ciências exatas aplicadas e tecnológicas, v.4, n.2. p.1-13, 2012.
CONTESINI, F. J. et al. Aspergillus sp. lipase: potential biocatalyst for industrial use. Journal of Molecular Catalysis B: Enzymatic, v. 67, n. 3, p. 163-171, 2010.

COSTA, P. A. et al. Changes in soil pore network in response to twenty-three years of irrigation in a tropical semiarid pasture from northeast Brazil. Soil \& Tillage Research, v. 137, p. 23-32, 2014.

DAMASCENO, F. R. C; CAMMAROTA, M. C.; FREIRE, D. M. G. The combined use of a biosurfactant and an enzyme preparation to treat an effluent with a high fat content. Colloids and Surfaces B: Biointerfaces, v. 95, p. 241-246, 2012.

DEVI, S.; SIVAKUMAR, T. Production and characterization of alkaline lipase from Aspergillus awamori. Int. J. Adv. Res. Biol. Sci, v. 1, n. 8, p. 212228, 2014.

DOBREV, G. et al. Lipase biosynthesis by Aspergillus carbonarius in a nutrient medium containing products and byproducts from the oleochemical industry. Biocatalysis and Agricultural Biotechnology, v.4, p.77-82, 2014.

DUMORE, N. S.; MUKHOPADHYAY, M. Removal of oil and grease using immobilized triacylglycerin lipase. International Biodeterioration \& Biodegradation, v. 68, p. 65-70, 2012.

GASPARIN, F. G. M. et al. Produção de Lipase e Biossurfactante por Isolado de Efluente de Laticínio. BBR-Biochemistry and Biotechnology Reports, v. 1, n. 1, p. 28-31, 2012.

GOPINATH, S. C. B. et al. Strategies to chararcterize fungal lipases for applications in medicine and dairy industry. BioMed research international, ID154549, p.1-10, 2013.

HASAN, F.; SHAH, A. A.; HAMEED, A. Industrial applications of microbial lipases. Enzyme and Microbial Technology, v. 39, n. 2, p. 235-251, 2006.

HOSSEINPOUR, M. N. et al. Lipase production in solid state fermentation using Aspergillus niger: Response surface methodology. International Journal of Engineering, v. 25, n. 3, p. 151-159, 2012.

JOSHI, V. K.; WALIA, A.; RANA, N. S. Production of Bioethanol from Food Industry Waste: Microbiology, Biochemistry and Technology. In: Biomass Conversion, p. 251-311, 2012.

$\mathrm{KLICH}, \mathrm{M}$. A. Identification of common Aspergillus species. The Netherlands: Centraalbureau voor Schimmelcultures, P. 116, 2002. 
LAACHARI, F. et al. Higher tolerance of a novel lipase from Aspergillus flavus to the presence of free fatty acids at lipid/water interface. African Journal of Biochemistry Research, v. 9, n. 1, p. 9-17, 2015.

LEE, S. et al. Screening for novel lipolytic enzymes from uncultured soil microorganisms. Applied microbiology and biotechnology, v. 65, n. 6, p. 720726, 2004.

LIMA, B. F. et al. Seleção de meios de produção de lipase por amostras de Aspergillus $\mathrm{sp}$ isoladas da caatinga de Pernambuco. e-Xacta, v. 7, n. 1, 2014.

LIN, C. S. K. et al. Food waste as a valuable resource for the production of chemicals, materials and fuels. Current situation and global perspective. Energy \& Environmental Science, v. 6, n. 2, p. 426-464, 2013.

LIU, C. et al. Response surface optimization of fermentation conditions for producing xylanase by Aspergillus niger SL-05. Journal of industrial microbiology \& biotechnology, v. 35, n. 7, p. $703-$ 711, 2008.

LIU, X. et al. Systematics-guided bioprospecting for bioactive microbial natural products. Antonie van Leeuwenhoek, v. 101, n. 1, p. 55-66, 2012.

MACEDO, L. N. et al. Estudo da Influência de Variáveis de Processo na Produção de Lipases por Fungo Filamentoso. In: Simpósio Nacional de Bioprocessos, 07, 2009, Rio de Janeiro. Anais.... Natal RN: Embrapa, P. 01-05, 2009.

MALDONATO, R. R.; MACEDO, G. A.; RODRIGUES, M. I. Lipase Production Using Microorganisms from Different Agro-Industrial By-Products. International Journal of Applied Science and Technology, v.4, n.1, p. 108-115, 2014.

MANOCHA, M. S., SAN-BLAS, G., Centeno, S.1980. Lipid composition of Paracoccidioides brasiliensis: possible correlation with virulence of different strains. J. GEN. MICROBIOL. Sabouraudia, v. 117:147-154, 1980.

MARQUES, T. A. et al. Utilization of dairy effluent as alternative fermentation medium for microbial lipase production. Romanian Biotechnological Letters, v. 19, n. 1, p. 9042-9050, 2014.

MARTINS, V. G; KALIL, S. J; COSTA, J. A. V. Lipases and biosurfactant production by solid state fermentation for utilization in bioremediation of vegetable oils and hydrocarbons. Química Nova, v. 31, n. 8, p. 1942-1947, 2008.
MENDES, A. A. et al. Aplicação de lipases no tratamento de águas residuárias com elevados teores de lipídeos. Química Nova, v. 28, n. 2, p. 296-305, 2005.

MONCIARDINI, P. et al. Discovering new bioactive molecules from microbial sources. Microbial biotechnology, v. 7, n. 3, p. 209-220, 2014.

MONTEIRO, M. C. P. Identificação de fungos dos gêneros Aspergillus e Penicillium em solos preservados do cerrado. 2012. 76 p. Dissertação (Mestrado em Microbiologia Agrícola)-Universidade Federal de Lavras, Lavras, 2012.

NANGUL, A. et al. Microorganisms: a marvelous source of single cell proteins. Journal of Microbiology, Biotechnology and Food Sciences, v. 3, n. 1, p. 15-18, 2013.

NAZ, S.; JADHAV, S. K. Studies of the Estimation of Lipase Production Capability of Some Fungal Species and their Application in Oil Spillage Degradation. International Journal of Science and Research (IJSR), v. 4, n. 1, p. 2319-7064, 2015.

NOTARNICOLA, B. et al. Progress in working towards a more sustainable agri-food industry. Journal of Cleaner Production, v. 28, p. 1-8, 2012.

PANESAR, P. S.; KENNEDY, J. F. Biotechnological approaches for the value addition of whey. Critical reviews in biotechnology, v. 32, n. 4, p. 327-348, 2012.

PAPANIKOLAOU, S. et al. Industrial derivative of tallow: a promising renewable substrate for microbial lipid, single-cell protein and lipase production by Yarrowia lipolytica. Electron. J. Biotechnol., Valparaíso, v. 10, n. 3, jul. 2007.

PITT, J. I. The genus Penicillium and its teleomorphic states Eupenicillium and Talaromyces. Academic Press, Inc., New York. 1979.

PLANTE, A. F., STONE, M. M., MCGILL, W. B. The Metabolic Physiology of Soil Microorganisms. Soil Microbiology, Ecology and Biochemistry, p. 245, Philadelphia, PA. USA. E. Eldor A. Pau. 2014. Disponível em: https://books.google.com.br Acesso em 02. 09 de 2014. ISBN 978-0-12-415955-6.

PLEISSNER, D. et al. Fungal hydrolysis in submerged fermentation for food waste treatment and fermentation feedstock preparation. Bioresource technology, v. 158, p. 48-54, 2014.

REIS, A. C. S. Clima da caatinga. Anais da academia brasileira de ciências, v. 48, n. 2, p. 325-335, 1976. 
ROVEDA, M; HEMKEMEIER, M; COLLA, L. M. Evaluation of lipase production using different strains of microorganisms isolated from dairy effluent through submerged fermentation. Food Science and Technology (Campinas), v. 30, n. 1, p. 126-131, 2010.

SHARMA, R.; CHISTI, Y.; BANERJEE, Y. C. Production, purification, characterization and applications of lipases. Biotechnology Advances, v. 19, p. 627-662, 2001.

SILVA, G. S.; BRUNO, L. M.; CASTRO, H. F. Seleção e Imobilização de Fungos Filamentosos Produtores de Lipase Intracelular. Quim. Nova, Fortaleza, v. 5, n. 8, p.01-07, ago. 2009.

SINGH, A. K.; MUKHOPADHYAY, M. Overview of fungal lipase: a review. Applied biochemistry and biotechnology, v. 166, n. 2, p. 486-520, 2012.

SMRITHI, S. et al. Bioprospecting of Microbes Producing Commercially Useful Products. PHARMANEST - An International Journal of Advances in Pharmaceutical Sciences, v. 4, n. 6, p. 1419-1426, 2013.

SOARES, C. M. F. et al. Characterization and utilization of Candida rugosa lipase immobilized on controlled pore silica. Applied Biochemistry Biotechnology, v. 77/79, n.2, p. 745-757, 1999.
SUBHASH, G. V; MOHAN, S. V. Lipid accumulation for biodiesel production by oleaginous fungus Aspergillus awamori: Influence of critical factors. Fuel, v. 116, p. 509-515, 2014.

SUNG, K.; KIM, Ki S.; PARK, S. Enhancing degradation of total petroleum hydrocarbons and uptake of heavy metals in a wetland microcosm planted with Phragmites communis by humic acids addition. International journal of phytoremediation, v. 15, n. 6 , p. 536-549, 2013.

TUDORACHE, M. et al. Efficient bio-conversion of glycerol to glycerol carbonate catalyzed by lipase extracted from Aspergillus niger. Green Chemistry, v. 14, n. 2, p. 478-482, 2012.

VADLAMANI, S.; PARCHA, S. R.. Studies on industrially important alkaline protease production from locally isolated superior microbial strain from soil microorganisms. International Journal of Biotechnology Applications, v. 3, n. 3, p. 102-105, 2011.

WANG, L. J. et al. Production of bioenergy and bioproducts from food processing wastes: a review. Transactions of the ASABE, v. 56, n. 1, p. 217-229, 2013.

ZEN, C. K. et al. INDUÇÃO DA SÍNTESE DE LIPÍDIOS E PROTEÍNAS POR Aspergillus niger. Revista CIATEC-UPF, v. 6, n. 2, p. 40-47, 2014. 